\title{
EVALUASI KONDISI 1KM RUAS JALAN M.H. THAMRIN MENGGUNAKAN METODE IRAP UNTUK MENCAPAI STAR RATING 4
}

\author{
Andre Joshua ${ }^{1}$ dan Ni Luh Putu Shinta Eka Setyarini ${ }^{2}$ \\ ${ }^{1}$ Program Studi Sarjana Teknik Sipil, Universitas Tarumanagara, Jl. Letjen S. Parman No.1 Jakarta \\ andrej.ts@stu.untar.ac.id \\ ${ }^{2}$ Program Studi Sarjana Teknik Sipil, Universitas Tarumanagara, Jl. Letjen S. Parman No.1 Jakarta \\ niluhs@ft.untar.ac.id
}

Masuk: 11-01-2021, revisi: 16-02-2021, diterima untuk diterbitkan: 17-02-2021

\begin{abstract}
The number of road accidents in Indonesia is very high and continues to increase, one of the causes is that there are still many roads that have not applied specific safety principles in their planning designs. To overcome this, it is necessary to implement a strategy to improve road safety using existing methods. In this study, the IRAP method was used to improve the safety of the M.H. Thamrin to achieve a 4 star rating.From the results of the study, it was found that the existing road segment was very good for vehicle occupant because it had reached a 5 star, it was functional for motorcyclist and bicyclist because it had reached 3 stars, but it was still dangerous for pedestrian because only reaches 2 stars. So it is necessary to do a countermeasure to increase the star rating to 4 stars for all road users. So that we get a final star rating of 5 stars on vehicle occupant and motorcyclist, 4 stars for bicyclist and pedestrian. By calculating BCR, the result is more than 1, which means that the treatment option is feasible to be realized.
\end{abstract}

Keywords: accident, IRAP, M.H. Thamrin Road.

\begin{abstract}
ABSTRAK
Jumlah kecelakaan di jalan raya di Indonesia sangatlah tinggi dan terus meningkat, salah satu penyebabnya adalah masih banyaknya ruas jalan yang belum menerapkan prinsip-prinsip keselamatan secara khusus dalam desain perencanaannya. Untuk mengatasi hal tersebut, perlu dilakukan strategi peningkatkan keselamatan jalan menggunakan metode yang ada. Pada penelitian ini digunakan metode IRAP untuk meningkatkan keselamatan ruas jalan M.H. Thamrin untuk mencapai star rating 4. Dari hasil penelitian ditemukan bahwa ruas jalan eksisting sudah sangat bagus bagi moda kendaraan berpenumpang karena sudah mencapai bintang 5, sudah laik fungsi bagi moda sepeda motor dan sepeda karena sudah mencapai bintang 3, namun masih berbahaya bagi pejalan kaki karena hanya mencapai bintang 2. Maka perlu dilakukan countermeasure untuk meningkatkan star rating menjadi bintang 4 pada semua pengguna jalan. Sehingga didapat star rating akhir bintang 5 pada kendaraan berpenumpang dan sepeda motor, bintang 4 pada pesepeda dan pejalan kaki. Melalui perhitungan BCR didapat hasil lebih dari 1, yang berarti opsi penanganan layak untuk di realisasikan.
\end{abstract}

Kata kunci: Kecelakaan, IRAP, Jalan M.H. Thamrin.

\section{PENDAHULUAN}

Kecelakaan adalah suatu peristiwa di jalan yang tidak inginkan dan tidak disengaja, melibatkan kendaraan yang sedang bergerak dengan pengguna jalan lainnya dan mengakibatkan korban jiwa atau kerugian harga benda (Supiyono, 2018). Menurut (Ruktiningsih, 2017), semakin tinggi jumlah kecelakaan di suatu wilayah maka mengindikasikan semakin rendahnya tingkat keselamatan lalu lintas dalam wilayah tersebut. Kecelakaan disebut fatal apabila adanya korban meninggal dunia.

Jumlah kecelakaan di jalan raya di Indonesia sangatlah tinggi dan terus meningkat, berdasarkan data dari Korlantas Polri di sepanjang tahun 2018 saja terjadi 196.457 kejadian. Peningkatan kecelakaan lalu lintas tidak boleh disepelekan, karena pada dasarnya kecelakaan lalu lintas adalah predictable dan preventable (Setyarini dan Lukito, 2020). Seperti contoh kecelakaan lalu lintas yang sering terjadi adalah akibat fasilitas perlengkapan jalan seperti rambu, marka dan pembatas jalan yang sudah dibuat tetapi kurang berfungsi dengan baik karena jumlah dan ketinggian nya yang belum memadai (Setyarini, et al., 2019). 
Berdasarkan Asia Development Bank, pejalan kaki, pengguna kendaraan bermotor dan tidak bermotor lebih sering menjadi korban kecelakaan lalu lintas di negara berkembang dari pada negara maju, karena pada negara berkembang jumlah fasilitasnya belum memadai. Dalam penelitian yang dilakukan Direktorat Jendral Perhubungan Darat, faktor yang menjadi penyebab terjadinya kecelakaan adalah pengemudi $(93,52 \%)$, kendaraan $(2,76 \%)$, jalan $(3,23 \%)$, dan lingkungan $(0,49 \%)$. Berdasarkan data tersebut untuk meminimalkan defisiensi keselamatan infrastruktur jalan, maka ada tiga aspek penting yang harus dilakukan untuk mewujudkan ruas jalan berkeselamatan, sesuai dengan Undang-Undang No. 22 Tahun 2009 tentang Lalu Lintas Angkutan jalan, yaitu Self-explaining, Self-inforcing, dan Forgiving road (Sugiharto, et al., 2015).

Permasalahan keselamatan jalan merupakan hal yang kompleks, sehingga memerlukan pertimbangan terhadap berbagai faktor terkait, yang memerlukan kemampuan konseptual, toleransi ketidakjelasan dan kesadaran terhadap situasi yang saling terkait (Mayastinasari, 2018). Demi meningkatkan keselamatan jalan pada tahap operasi dan pemeliharaan, harus menemukan dan memperbaiki masalah keselamatan jalan, supaya tidak terjadi kecelakaan yang berulang pada tempat atau ruas jalan yang sama (Sianturi \& Setyarini, 2020).

Pemerintah sebagai penyelenggara jalan seperti dijelaskan dalam Pasal 23 Undang Undang Republik Indonesia No.22 Tahun 2009 menyatakan, bahwa Pemerintah sebagai penyelenggara jalan berkewajiban memberi rasa aman dan selamat sebagai suatu tuntutan jalan berkeselamatan, sehingga pengguna jalan merasa aman ketika sedang melakukan perjalanan. Demikian juga pasal 30 Undang Undang Republik Indonesia No.38 Tahun 2004 dan pasal 102 Peraturan Pemerintah Republik Indonesia No.34 Tahun 2006 yang menyatakan jalan harus memenuhi persyaratan laik fungsi.

Menurut Peraturan Menteri Pekerjaan Umum nomor 11 / PRT / M / 2010 tentang Tata Cara dan Persyaratan Laik Fungsi Jalan, laik fungsi jalan adalah kondisi suatu ruas jalan yang memenuhi persyaratan teknis kelaikan jalan untuk memberikan keselamatan bagi penggunanya, dan persyaratan administratif yang memberikan kepastian hukum bagi penyelenggara jalan dan pengguna jalan, sehingga jalan tersebut dapat dioperasikan untuk umum. Uji Laik Fungsi jalan sangat diperlukan untuk menekan angka kecelakaan lalu lintas, Laik fungsi jalan merupakan gabungan dari inspeksi keselamatan jalan dan audit keselamatan jalan (Pandey, 2015).

Gambar 1. adalah hubungan strategi peningkatan keselamatan jalan yang dapat digunakan oleh auditor keselamatan jalan dalam peningkatan keselamatan jalan. Auditor keselamatan jalan juga harus ahli dalam bidang nya, dan berpengalaman dengan keterampilan yang memadai dalam aturan dan praktik keselamatan jalan, investigasi, penghindaran kecelakaan, rekayasa lalu lintas dan desain jalan (Setyarini dan Putranto, 2020).

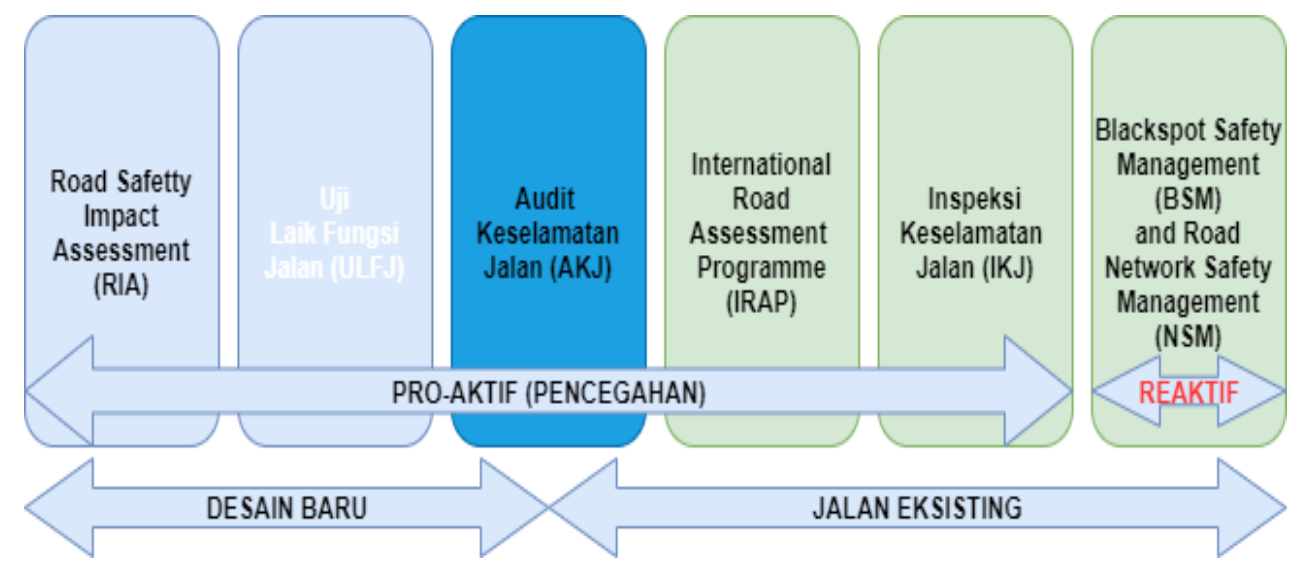

Gambar 1. Strategi peningkatan keselamatan jalan

Beberapa metode peningkatan keselamatan jalan tersebut penting harus segera dilakukan, untuk meminimalkan defisiensi keselamatan infrastruktur jalan eksisting yang melayani lalu lintas kendaraan. penerapan nya berdasarkan data kecelakaan serta pengukuran langsung di lapangan terhadap penyimpangan geometrik dan jarak pandang, kondisi kerusakan perkerasan, dan ketidakharmonisan fasilitas perlengkapan jalan terhadap fungsi jalan (Mulyono et al., 2015). Dari setiap metode yang ada dihasilkan suatu rekomendasi penanganan baik untuk mencegah maupun mengurangi kecelakaan, oleh karena itu untuk meningkatkan keselamatan jalan yang terpenting adalah adanya teknik-teknik penanganan kecelakaan yang efektif, dan mampu mencegah ataupun mengurangi kecelakaan serta efisien di dalam pembiayaan (Rustijan dan J, 2015). 
International Road Assessment Programme (IRAP) adalah salah satu metode peningkatan keselamatan jalan untuk ruas jalan yang sudah beroperasi. IRAP telah mengembangkan metode yang dapat diterapkan langsung, meskipun demikian IRAP tetap mendorong dan memberikan kesempatan bagi negara-negara yang menjadi anggotanya untuk melakukan studi validasi, berkontribusi terhadap perkembangan model, dan menentukan parameter yang perlu dikalibrasi dengan kondisi lokal.

Dalam penelitian ini, peneliti mencoba mengevaluasi ruas Jalan M.H Thamrin yang berada di Jakarta Pusat sepanjang $1 \mathrm{~km}$ menggunakan metode IRAP. Seperti yang berada pada gambar 2. peneliti menjadikan titik A sebagai awal dan titik B patokan akhir dari ruas jalan yang akan ditinjau. Dari penelitian ini, peneliti bermaksud untuk mengetahui kondisi eksisting ruas Jalan M.H. Thamrin, serta menerapkan metode IRAP untuk meningkatkan star rating ruas Jalan M.H. Thamrin menjadi star rating bintang 4.

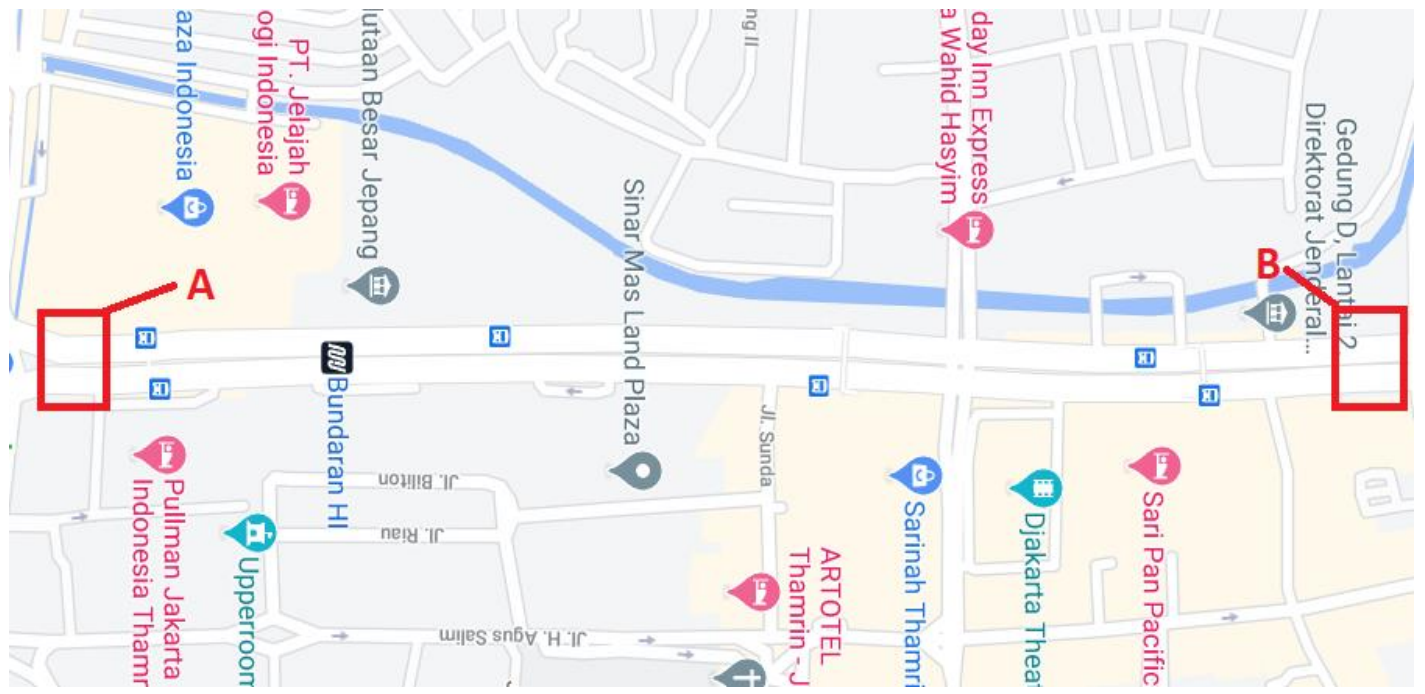

Gambar 2. Peta ruas jalan M.H. Thamrin yang akan dievaluasi (sumber: google maps)

Berdasarkan latar belakang, jurnal ini akan mengidentifikasi masalah yaitu:

1. Keselamatan jalan adalah masalah yang bergantung pada faktor jalan, lingkungannya, kendaraan, dan perilaku pengguna jalan.

2. Diperlukan peningkatan kualitas keselamatan infrastruktur jalan di Indonesia untuk menurunkan tingkat risiko terjadinya kecelakaan, oleh karena itu Pemerintah melakukan upaya penanggulangan dengan menentukan ruas ruas jalan yang mempunyai tingkat keselamatan yang buruk, untuk selanjutnya diperbaiki baik jalan ataupun perlengkapannya.

3. Perbaikan elemen-elemen pada jalan Protokol masih menjadi kesulitan karena tata guna lahan.

4. Metode International Road Assessment Programme (IRAP) sudah banyak diterapkan di berbagai negara untuk meningkatkan keselamatan jalan.

Berdasarkan rumusan masalah, tujuan dari penelitian ini adalah

1. Untuk mengetahui Safer Road Invesment Plan (SRIP) dan mengetahui kondisi star rating kondisi awal jalan M.H. Thamrin.

2. Untuk mengetahui bagaimana mencapai star rating 4 ruas jalan M.H. Thamrin menggunakan metode IRAP.

3. Mengetahui keunggulan dari metode IRAP dengan cara penanganan ruas jalan, dan perhitungan Benefit Cost Ratio (BCR) dari penanganan ruas jalan tersebut.

\section{Internasional Road Assassment Programme (IRAP)}

International Road Assessment Programme (IRAP) adalah program penilaian suatu ruas jalan yang bertujuan untuk menyelamatkan banyak nyawa melalui jalan yang berkeselamatan. IRAP berhasil mengembangkan cara penilaian keselamatan jalan bagi pengguna jalan melalui penentuan nilai atau skor risiko yang mungkin terjadi akibat elemen infrastruktur jalan yang disebut dengan Star Rating Score (SRS). Nilai SRS menunjukkan peluang terjadinya kecelakaan serta tingkat keparahan yang akan dialami apabila terjadi kecelakaan lalulintas pada suatu ruas jalan. Nilai SRS yang tinggi menggambarkan besarnya peluang terjadinya kecelakaan. Sebaliknya nilai SRS yang rendah menggambarkan kecilnya peluang terjadi kecelakaan. Hasil perhitungan SRS tersebut kemudian dikonversikan ke dalam peringkat bintang (star rating) yang didesain dari bintang satu hingga bintang lima. Apabila hasil nilai SRS 
rendah, maka semakin tinggi star rating nya, begitupun sebaliknya apabila hasil nilai SRS tinggi, maka semakin rendah star rating nya.

\section{Star rating}

Star rating merupakan konsep penilaian keselamatan jalan dari IRAP berdasarkan kondisi elemen-elemen infrastruktur ruas jalan yang berupa peringkat bintang. Ukuran yang digunakan IRAP dalam melakukan penilaian kinerja keselamatan jalan adalah angka faktor risiko kecelakaan dari elemen-elemen infrastruktur jalan dalam berbagai kondisi. Hasil star rating berupa bintang 1 (satu) sampai dengan bintang 5 (lima) yang ditentukan berdasarkan pengklasifikasian Star Rating Score (SRS) (Lawson, 2011). SRS tersebut menunjukkan besar risiko terjadinya tabrakan yang dianggap menyebabkan kecelakaan berat yang mengakibatkan korban meninggal dunia dan luka berat. Setelah SRS didapat, kemudian dilakukan klasifikasi seperti pada Tabel 1. sehingga menghasilkan penilaian bintang 1 (satu) sampai dengan bintang 5 (lima). Bintang-bintang tersebut didefinisikan sebagai berikut :

1. Bintang 4 dan bintang 5 adalah jalan yang elemen-elemen jalan nya sudah sesuai dengan semua pengguna jalan, sehingga jalan dengan kondisi bintang 4 dan 5 sudah berkeselamatan tinggi.

2. Bintang 3 adalah jalan yang sudah dianggap laik fungsi, sudah sesuai dan layak dilalui kendaraan, namun masih berpotensi terjadinya kecelakaan.

3. Bintang 2 adalah jalan yang buruk dan tidak laik fungsi, karena elemen-elemen jalannya yang kurang memadai.

4. Bintang 1 adalah kondisi jalan yang paling buruk, dapat di katakan tidak layak dilewati kendaraan karena memiliki risiko kecelakaan yang sangat tinggi.

Tabel 1. Tabel klasifikasi dan kode warna star rating score

\begin{tabular}{cccc}
\hline \multirow{2}{*}{ Star Rating } & \multicolumn{3}{c}{ Star Rating Score } \\
\cline { 2 - 4 } & Vehicle Occupants and Motorcyclists & Bicyclists & Pedestrian \\
\hline 5 & 0 to $<2.5$ & 0 to $<5$ & 0 to $<5$ \\
4 & 2.5 to $<5$ & 5 to $<10$ & 5 to $<15$ \\
3 & 5 to $<12.5$ & 10 to $<30$ & 15 to $<40$ \\
2 & 12.5 to $<22.5$ & 30 to $<60$ & 40 to $<90$ \\
1 & $22.5+$ & $60+$ & $90+$
\end{tabular}

\section{Countermeasure}

Countermeasure merupakan bagian penanganan dari salah satu protokol IRAP yaitu Safer Road Invesment Plan yang bertujuan untuk meningkatkan star rating awal eksisting jalan serta mengurangi risiko kematian dan cedera serius. Countermeasure dilakukan dengan cara melakukan perubahan-perubahan pada elemen jalan yang di anggap membahayakan dan dapat menyebabkan terjadinya kecelakaan lalulintas. Penerapan jenis penanganan harus mengikuti ketentuan yang ditetapkan IRAP agar tidak terjadi adanya duplikasi untuk elemen jalan yang sama (IRAP, https://resources.irap.org, 2015).

\section{Benefit Cost Ratio (BCR)}

Pada IRAP Benefit Cost Ratio (BCR) digunakan untuk membandingkan antara biaya yang dikeluarkan untuk pemasangan opsi penanggulanan elemen jalan dari countermeasure, terhadap estimasi nyawa yang akan terselamatkan beserta nilai keuntungannya pada jangka waktu 20 Tahun (IRAP, https://resources.irap.org, 2015).

\section{METODE PENELITIAN}

\section{Tahapan studi pustaka}

Pada tahap ini peneliti melakukan studi pustaka, yaitu memperdalam pengetahuan tentang metode Internasional Road Assessment Programme (IRAP) melalui pembacaan tentang jurnal-jurnal terkait, studi terdahulu, dan melalui IRAP Methodology. Selanjutnya dilakukan pengumpulan data-data mendukung seputar kondisi ruas jalan yang akan di teliti yaitu ruas Jalan M.H. Thamrin. Data yang dikumpulkan harus dapat menambah kredibilitas hasil penelitian yang dilakukan. 


\section{Tahapan rumusan dan ruang lingkup penelitian}

Pada tahap ini peneliti akan merumuskan masalah yang nantinya akan menjadi tujuan penelitian dari penulis, adapun rumusan masalah dalam penelitian ini adalah untuk mengetahui bagaimana metode International Road Assessment Programme (IRAP) untuk meningkatkan keselamatan suatu ruas jalan menjadi star rating bintang 4 . Penulis juga membatasi ruang lingkup penelitian lebih spesifik agar penelitian lebih terarah dan terfokus.

\section{Tahapan pengambilan data primer}

Pada tahap pengambilan data primer, peneliti memilih menggunakan bantuan Google Streetview dan Google Earth View untuk mengamati kondisi eksisting ruas Jalan M.H. Thamrin.

\section{Tahapan pengambilan data sekunder}

Pada tahap ini, peneliti akan mengambil data sekunder dari ruas jalan M.H. Thamrin. Data yang diperlukan adalah Lalu Lintas Harian Rata-Rata (LHR), data kecelakaan, dan Rancangan Anggaran Biaya (RAB). Data LHR didapat dari Instansi terakit yaitu Dinas Perhubungan DKI Jakarta, data kecelakaan didapat dari Badan Pusat Statistik Provinsi DKI Jakarta, dan data RAB didapat dari Balai Besar Pelaksanaan Jalan Nasional VI (BBPJN VI) DKI Jakarta, Jabar dan Banten, yang diperlukan untuk mencari star rating score.

\section{Tahap coding}

Setelah dilakukan survey ruas jalan melalui Google Stree View serta pengumpulan data primer dan sekunder, selanjutnya pada penelitian ini akan dilakukan coding untuk mendapatkan star rating awal. Coding attributes mengikuti IRAP Coding Manual Drive on Left Edition 2019.

\section{Star rating awal}

Pada tahap ini, peneliti akan mendapatkan kondisi star rating score eksisting ruas Jalan M.H. Thamrin untuk empat tipe pengguna jalan yaitu kendaraan berpenumpang, sepeda motor, pesepeda, dan pejalan kaki setelah dilakukan proses coding untuk setiap 100 meter segmen jalan.

\section{Tahapan mengevaluasi atribut yang di nilai bermasalah}

Setelah mendapatkan star rating eksisting ruas Jalan M.H. Thamrin, pada tahap ini peneliti akan mengevaluasi elemen-elemen apa saja yang membahayakan atau dapat menyebabkan terjadinya kecelakaan pada pengguna jalan ruas Jalan M.H. Thamrin, lalu memberikan rekomendasi terkait elemen apa saja yang dibutuhkan agar memberikan peningkatan star rating menjadi bintang 4.

\section{Tahapan menghitung biaya alternatif serta BCR}

Pada tahap ini peneliti akan menghitung beberapa alternatif perubahan elemen-elemen jalan yang dilakukan. Pada tahap ini pertimbangan yang perlu diperhatikan adalah agar biaya konstruksi yang keluar berbanding lurus dengan jumlah nyawa yang terselamatkan kedepannya.

\section{Rating score akhir}

Setelah dilakukan berbagai alternatif peningkatan elemen-elemen jalan yang telah dilakukan sebelumnya. pada tahap ini, peneliti akan mendapat hasil akhir star rating dari ruas Jalan M.H. Thamrin.

\section{Kesimpulan dan saran}

Pada tahap kesimpulan dan saran maka peneliti akan memberikan rekomendasi terkait hal-hal apa saja dari penelitian ini yang dapat meningkatkan keselamatan lalu lintas pada ruas Jalan M.H. Thamrin. Dengan harapan hasil penelitian yang diberikan dapat mengurangi resiko terjadinya kecelakaan di ruas Jalan M.H. Thamrin.

\section{HASIL DAN PEMBAHASAN}

\section{Coding hasil survei kondisi eksisting ruas jalan M.H. Thamrin}

Data yang diperoleh dari survei melalui bantuan Google Street View dan Google Maps akan di coding untuk mendapatkan Star Rating kondisi eksisting ruas jalan M.H. Thamrin. Proses coding dilakukan untuk setiap 100m segmen jalan. Tabel 2. Merupakan hasil coding dari jalan eksisting 
Tabel 2. Hasil coding atribut jalan eksisting

\begin{tabular}{|c|c|c|}
\hline No. & Attributes & Category \\
\hline 1 & Lane Width & $\operatorname{Narrow}(>=0 m$ to $2.75 \mathrm{~m})$ \\
\hline 2 & Curvature & Straight or gently curving \\
\hline 3 & Quality of Curve & Adequate \\
\hline 4 & Delineation & Adequate \\
\hline 5 & Shoulder rumble strips & Not present \\
\hline 6 & Road condition & Good \\
\hline 7 & Grade & $0 \%$ to $<7,5 \%$ \\
\hline 8 & Skid resistance / grip & Sealed-medium \\
\hline 9 & Roadside severity distance (driver side) & $1 m$ to $<5 m$ \\
\hline 10 & $\begin{array}{l}\text { Roadside severity distance (passanger } \\
\text { side) }\end{array}$ & $1 m$ to $<5 m$ \\
\hline 11 & Roadside severity object (driver side) & Safety barrier - concrete \\
\hline 12 & Roadside severity object (passanger side) & Non-frangible sign $/$ post/pole $(>=10 \mathrm{~cm}$ diameter $)$ \\
\hline 13 & Paved shoulder width & None \\
\hline 14 & Centreline rumble strip & Not present \\
\hline 15 & Median Type & Safety barrier - concrete \\
\hline 16 & Number of Lanes & Four or more \\
\hline 17 & Intersection Type & None \\
\hline 18 & Intersection Quality & Adequate \\
\hline 19 & Street Lighting & Present \\
\hline 20 & Sight distance & Adequate \\
\hline 21 & Intersection Channelisation & Not present \\
\hline 22 & Speed management/traffic calming & Not present \\
\hline 23 & Property access points & High density \\
\hline 24 & Service road & Not present \\
\hline 25 & Facilities for motorcycles & None \\
\hline 26 & Facilities for Bicycles & None \\
\hline 27 & Side Friction & Low \\
\hline 28 & Sidewalk provision (driver side) & None \\
\hline 29 & Sidewalk provision (passanger side) & Physical barrier \\
\hline 30 & Pedestrian Crossing Facilities & No facility \\
\hline 31 & Pedestrian crossing quality & Adequate \\
\hline 32 & Vehicle Parking & None \\
\hline 33 & Median Traversability & Traversable \\
\hline 34 & Operating Speed & $40 \mathrm{~km} / \mathrm{h}$ \\
\hline 35 & $\begin{array}{c}\text { Property access points (vehicle and } \\
\text { motorcyclist) }\end{array}$ & Commercial Access 1+ \\
\hline 36 & Diffrential speed & Not Present \\
\hline 37 & Pedestrian Fencing & None \\
\hline
\end{tabular}

\section{Star rating awal kendaraan berpenumpang}

Berdasarkan hasil coding menggunakan data eksisting ruas jalan M.H. Thamrin dan di lakukan perhitungan Star Rating Score (SRS) menggunakan rumus berikut: 
- SRS untuk Run-off (driver and passanger)

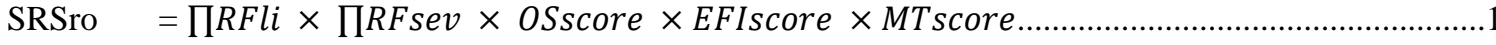

- SRS untuk Head-on (loss-of-control)

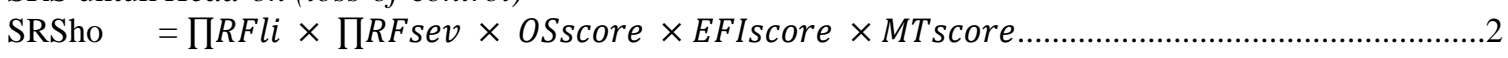

- SRS untuk Head-on (overtaking)

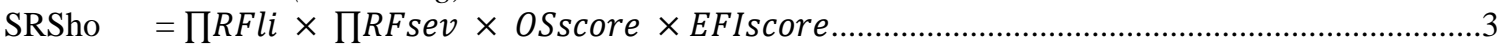

- SRS untuk Intersection

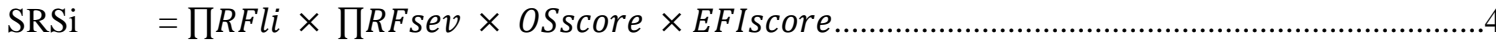

- SRS untuk Property Access

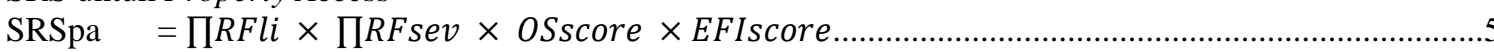

- SRS untuk Along

$\mathrm{SRSa}=\prod$ RFli $\times \prod$ RFsev $\times$ oSscore $\times$ EFIscore

Keterangan :

Li = Likelihood

Sev = Severity

Os = Operating speed

Mt = Median traversability

Efi = External flow influence

Maka pada Tabel 3. di dapatkan star rating awal untuk kategori pengguna jalan yaitu kendaraan berpenumpang dengan rekapitulasi segmen 1 sampai segmen 10

Tabel 3. Star rating awal kendaraan berpenumpang

\begin{tabular}{cc} 
Vehicle occupant star rating \\
\hline Segmen 1 & 5 \\
Segmen 2 & 5 \\
Segmen 3 & 5 \\
Segmen 4 & 5 \\
Segmen 5 & 5 \\
Segmen 6 & 5 \\
Segmen 7 & 5 \\
Segmen 8 & 5 \\
Segmen 9 & 5 \\
Segmen 10 & 5
\end{tabular}

Berdasarkan tabel 3. di simpulkan bahwa kondisi eksisting ruas jalan M.H. Thamrin sudah sangat layak di gunakan untuk kendaraan berpenumpang karena sudah mencapai star rating 5, yaitu peringkat bintang yang paling tinggi. Artinya dari segi elemen jalan sudah sangat sesuai dengan fungsi nya bagi kendaraan berpenumpang.

\section{Star rating awal sepeda motor}

Berdasarkan hasil coding menggunakan data eksisting ruas jalan M.H. Thamrin dan di lakukan perhitungan Star Rating Score (SRS) menggunakan rumus berikut:

- SRS untuk Run-off (driver and passanger)

SRSro $=\prod R F l i \times \prod R F$ sev $\times$ OSscore $\times$ EFIscore $\times$ MTscore.

- SRS untuk Head-on (loss-of-control)

$\mathrm{SRSho}=\prod$ RFli $\times \prod$ RFsev $\times$ OSscore $\times$ EFIscore $\times$ MTscore

- SRS untuk Head-on (overtaking)

SRSho $=\prod$ RFli $\times \prod$ RFsev $\times$ OSscore $\times$ EFIscore

- SRS untuk Intersection

$\mathrm{SRSi}=\prod$ RFli $\times \prod$ RFsev $\times$ OSscore $\times$ EFIscore

- SRS untuk Property Access

$\mathrm{SRSpa}=\prod$ RFli $\times \prod$ RFsev $\times$ OSscore $\times$ EFIscore 
- SRS untuk Along

$\mathrm{SRSa}=\prod$ RFli $\times \prod R F$ sev $\times$ OSscore $\times$ EFIscore

Keterangan :

Li $\quad=$ Likelihood

Sev $=$ Severity

Os = Operating speed

$\mathrm{Mt}=$ Median traversability

Efi = External flow influence

Maka pada Tabel 4. di dapatkan star rating awal untuk kategori pengguna jalan yaitu sepeda motor dengan rekapitulasi segmen 1 sampai segmen 10

Tabel 4. Star rating awal sepeda motor

\begin{tabular}{cc} 
Motorcyclist star rating \\
\hline Segmen 1 & 3 \\
Segmen 2 & 3 \\
Segmen 3 & 3 \\
Segmen 4 & 3 \\
Segmen 5 & 3 \\
Segmen 6 & 3 \\
Segmen 7 & 3 \\
Segmen 8 & 3 \\
Segmen 9 & 3 \\
Segmen 10 & 3
\end{tabular}

Berdasarkan tabel 4. di simpulkan bahwa kondisi eksisting ruas jalan M.H. Thamrin sudah laik fungsi bagi pengguna sepeda motor karena sudah mencapai star rating 3, namun masih perlu di lakukan upaya peningkatan pada elemen ruas jalan M.H. Thamrin yang mempengaruhi keselamatan pengguna sepeda motor untuk mencapai star rating yang diinginkan yaitu bintang 4 .

\section{Star rating awal pesepeda}

Berdasarkan hasil coding menggunakan data eksisting ruas jalan M.H. Thamrin dan di lakukan perhitungan Star Rating Score (SRS) menggunakan rumus berikut:

- SRS untuk Run-off (driver and passanger) SRSro $=\prod R F l i \times \prod R F s e v \times$ OSscore $\times$ EFIscore

- $\quad$ SRS untuk Along

$$
\mathrm{SRSa}=\prod \text { RFli } \times \prod \text { RFsev } \times \text { OSscore } \times \text { EFIscore }
$$

- SRS untuk Intersection

$\mathrm{SRSi}=\prod$ RFli $\times \prod$ RFsev $\times$ OSscore $\times$ EFIscore

Keterangan :

$$
\begin{array}{ll}
\mathrm{Li} & =\text { Likelihood } \\
\mathrm{Sev} & =\text { Severity } \\
\mathrm{Os} & =\text { Operating speed } \\
\mathrm{Efi} & =\text { External flow influence }
\end{array}
$$

maka pada Tabel 5. di dapatkan star rating awal untuk kategori pengguna jalan yaitu pesepeda dengan rekapitulasi segmen 1 sampai segmen 10 
Tabel 5. Star rating awal pesepeda

\begin{tabular}{cc}
\multicolumn{2}{c}{ Bicyclist star rating } \\
\hline Segmen 1 & 4 \\
Segmen 2 & 4 \\
Segmen 3 & 3 \\
Segmen 4 & 3 \\
Segmen 5 & 3 \\
Segmen 6 & 3 \\
Segmen 7 & 3 \\
Segmen 8 & 4 \\
Segmen 9 & 4 \\
Segmen 10 & 4
\end{tabular}

Berdasarkan Tabel 5. di simpulkan bahwa kondisi eksisting ruas jalan M.H. Thamrin sudah sangat aman apabila dilalui oleh pengguna sepeda, karena berdasarkan star rating awal yang di dapat sudah mencapai bintang 4 . Namun masih perlu dilakukan upaya peningkatan elemen jalan pada segmen 3 sampai segmen 7 karena belum mencapai star rating yang di inginkan yaitu bintang 4 .

\section{Star rating awal pejalan kaki}

Berdasarkan hasil coding menggunakan data eksisting ruas jalan M.H. Thamrin dan di lakukan perhitungan Star Rating Score (SRS) menggunakan rumus berikut:

- SRS untuk Along (driver and passanger)

$\mathrm{SRSa}=\prod R F l i \times \prod R F$ sev $\times$ OSscore $\times$ EFIscore

- SRS untuk Crossing (inspected road)

SRSi $=\prod$ RFli $\times \prod$ RFsev $\times$ OSscore $\times$ EFIscore

- SRS untuk Crossing (side road)

SRSi $=\prod R F l i \times \prod R F$ sev $\times$ OSscore $\times$ EFIscore

Keterangan :

$\mathrm{Li} \quad=$ Likelihood

Sev $=$ Severity

Os = Operating speed

Efi = External flow influence

Maka pada Tabel 6. di dapatkan star rating awal untuk kategori pengguna jalan yaitu pejalan kaki dengan rekapitulasi segmen 1 sampai segmen 10

Tabel 6. Star rating awal pejalan kaki

\section{Pedestrian star rating}

$\begin{array}{cl}\text { Segmen 1 } & 2 \\ \text { Segmen 2 } & 2 \\ \text { Segmen 3 } & 2 \\ \text { Segmen 4 } & 2 \\ \text { Segmen 5 } & 2 \\ \text { Segmen 6 } & 2 \\ \text { Segmen 7 } & 4 \\ \text { Segmen 8 } & 2 \\ \text { Segmen 9 } & 5 \\ \text { Segmen 10 } & 2\end{array}$


Berdasarkan tabel 6. di simpulkan bahwa kondisi eksisting ruas jalan M.H. Thamrin untuk pejalan kaki dapat dikatakan sangat buruk karena sebagian besar hasil star rating yang diperoleh adalah bintang 2. Perlu dilakukan evaluasi bagi penyediaan fasilitas pejalan kaki di ruas jalan M.H. Thamrin demi keamanan, kenyamanan, serta keselamatan pejalan kaki di ruas jalan M.H. Thamrin mengingat ruas jalan M.H. Thamrin sering dilalui dan dipadati pejalan kaki karena termasuk dengan salah satu jalan utama di Jakarta dan merupakan pusat bisnis.

\section{Countermeasure}

Berdasarkan star rating awal yang sudah didapat dan menggunakan data FSI pada tabel 6.

Tabel 6. Nilai FSI untuk sepeda motor, pesepeda, pejalan Kaki

\begin{tabular}{cc}
\hline Moda & FSI \\
\hline Sepeda motor & 8,865558 \\
Pesepeda & 8,865558 \\
Pedestrian & 0,221639 \\
\hline
\end{tabular}

Maka dapat dilakukan countermeasure dengan melakukan beberapa treatment atau penanggulangan pada elemen jalan yang di anggap membahayakan. Pada tabel 7 sampai tabel 11 merupakan hasil dari countermeasure yang dibedakan berdasarkan pengguna jalan dan tipe kecelakaan

Tabel 7. Countermeasure motorcyclist dengan tipe kecelakaan along

\begin{tabular}{|c|c|c|c|c|}
\hline \multicolumn{5}{|c|}{ Motorcyclist(Along) } \\
\hline Attributes & Existing & outcome & Effectiveness & total reduction \\
\hline $\begin{array}{l}\text { Facilities for } \\
\text { motorcycles }\end{array}$ & None & $\begin{array}{c}\text { Segregated one-way } \\
\text { motorcycle path without } \\
\text { barrier }\end{array}$ & 95 & 8,42227982 \\
\hline
\end{tabular}

Tabel 8. Countermeasure bicyclist dengan tipe kecelakaan along

\begin{tabular}{|c|c|c|c|c|c|}
\hline \multicolumn{6}{|c|}{ Bicyclist(Along) } \\
\hline Attributes & $\begin{array}{l}\text { Existing } \\
\text { Category }\end{array}$ & Outcome & Effectiveness (\%) & $\begin{array}{c}\text { Reduction in FSI } \\
\text { (Simple Additive } \\
\text { Method) }\end{array}$ & $\begin{array}{c}\text { Reduction in } \\
\text { FSI }\end{array}$ \\
\hline $\begin{array}{c}\text { Speed } \\
\text { management/traffic } \\
\text { calming } \\
\end{array}$ & Not present & Present & 20 & 1,773111541 & 1,702187079 \\
\hline \multirow[t]{5}{*}{$\begin{array}{c}\text { Facilities for } \\
\text { Bicycles }\end{array}$} & None & $\begin{array}{l}\text { Signed shared } \\
\text { roadway }\end{array}$ & 5 & 0,443277885 & 0,42554677 \\
\hline & & & $\begin{array}{l}\text { Reduction } \\
\text { Additive }\end{array}$ & 2,216389426 & \\
\hline & & & $\begin{array}{l}\text { Reduction } \\
\text { Multiplied }\end{array}$ & 2,127733849 & \\
\hline & & & $M M C F$ & 0,96 & \\
\hline & & & Total Reduction & & 2,127733849 \\
\hline
\end{tabular}

Tabel 9. Countermeasure pedestrian dengan tipe kecelakaan along driver side

\begin{tabular}{ccccc}
\hline \multicolumn{4}{c}{ Pedestrian(Along Driver Side) } \\
\hline Attributes & Existing & Outcome & Effectiveness & $\begin{array}{c}\text { total } \\
\text { reduction }\end{array}$ \\
\hline $\begin{array}{c}\text { Speed } \\
\text { management/traffic } \\
\text { calming }\end{array}$ & $\begin{array}{c}\text { Not } \\
\text { present }\end{array}$ & Present & 20 & 0,044327789 \\
\hline
\end{tabular}


Tabel 10. Countermeasure pedestrian dengan tipe kecelakaan along passanger side

\begin{tabular}{|c|c|c|c|c|}
\hline \multicolumn{5}{|c|}{ Pedestrian(Along Passanger Side) } \\
\hline Attributes & Existing & Outcome & Effectiveness & $\begin{array}{c}\text { total } \\
\text { reduction }\end{array}$ \\
\hline $\begin{array}{c}\text { Speed } \\
\text { management/traffic } \\
\text { calming }\end{array}$ & $\begin{array}{c}\text { Not } \\
\text { present }\end{array}$ & Present & 20 & 0,044327789 \\
\hline
\end{tabular}

Tabel 11. Countermeasure pedestrian dengan tipe kecelakaan crossing

\begin{tabular}{|c|c|c|c|c|c|}
\hline \multicolumn{6}{|c|}{ Pedestrian (Crossing) } \\
\hline Attributes & $\begin{array}{l}\text { Existing } \\
\text { Category }\end{array}$ & Outcome & Effectiveness (\%) & $\begin{array}{c}\text { Reduction in FSI } \\
\text { (Simple Additive } \\
\text { Method) }\end{array}$ & $\begin{array}{c}\text { Reduction in } \\
\text { FSI }\end{array}$ \\
\hline Number of Lanes & $\begin{array}{c}\text { Four or } \\
\text { more }\end{array}$ & Three & 35 & 3,102945197 & 2,298477924 \\
\hline \multirow[t]{5}{*}{ Pedestrian Fencing } & None & Full length & 100 & 8,865557705 & 6,567079782 \\
\hline & & & Reduction Additive & 11,9685029 & \\
\hline & & & Reduction Multiplied & 8,865557705 & \\
\hline & & & $M M C F$ & 0,740740741 & \\
\hline & & & Total Reduction & & 8,865557705 \\
\hline
\end{tabular}

\section{Star rating akhir}

Berdasarkan opsi penanggulangan elemen jalan yang dianggap membahayakan melalui perhitungan countermeasure, maka pada tabel 12. merupakan star rating akhir untuk semua pengguna jalan pada segmen 1 sampai segmen 10 yang sudah mencapai star rating 4 .

Tabel 12. Star rating akhir semua tipe pengguna jalan segmen 1-10

\begin{tabular}{ccccccccccc}
\cline { 2 - 12 } & \multicolumn{10}{c}{ Star rating ruas jalan M.H Thamrin } \\
& Seg. & Seg. & Seg. & Seg. & Seg. & Seg. & Seg. & Seg. & Seg. & Seg. \\
& 1 & 2 & 3 & 4 & 5 & 6 & 7 & 8 & 9 & 10 \\
\hline Vehicle Occupant & 5 & 5 & 5 & 5 & 5 & 5 & 5 & 5 & 5 & 5 \\
\hline Motorcyclist & 5 & 5 & 5 & 5 & 5 & 5 & 5 & 5 & 5 & 5 \\
\hline Bicyclist & 4 & 4 & 4 & 4 & 4 & 4 & 4 & 4 & 4 & 4 \\
\hline Pedestrian & 4 & 4 & 4 & 4 & 4 & 4 & 4 & 4 & 4 & 4 \\
\hline
\end{tabular}

\section{Benefit Cost Ratio (BCR)}

Dilakukan perhitungan BCR pada tiap countermeasure yang dilakukan, untuk mengetahui keuntungan yang akan didapat berdasarkan nyawa yang terselamatkan, didapat perhitungan BCR yang dapat dilihat pada tabel 13 sampai dengan tabel 17 berikut.

Tabel 13. BCR motorcyclist dengan tipe kecelakaan along

\begin{tabular}{cccccc}
\hline \multicolumn{5}{c}{ Motorcyclist(Along) } \\
\hline Attribute & Category & $\begin{array}{c}\text { Total } \\
\text { Reduction }\end{array}$ & BCR & $\begin{array}{c}\text { Biaya } \\
\text { Pemasangan } \\
\text { ('000) }\end{array}$ & $\begin{array}{c}\text { Keuntungan } \\
\text { ('000) }\end{array}$ \\
\hline $\begin{array}{c}\text { Facilities } \\
\text { for } \\
\text { motorcycles }\end{array}$ & $\begin{array}{c}\text { Segregated one-way } \\
\text { motorcycle path without } \\
\text { barrier }\end{array}$ & 8,42228 & $\begin{array}{c}882,8458> \\
1 \text { (Feasible) }\end{array}$ & Rp. 87.028,05 & Rp. 76.832.341,11 \\
\hline
\end{tabular}


Tabel 14. BCR bicyclist dengan tipe kecelakaan along

\begin{tabular}{cccccc}
\hline \multicolumn{5}{c}{ Bicyclist(Along) } \\
\hline Attribute & Category & $\begin{array}{c}\text { Total } \\
\text { Reduction }\end{array}$ & BCR & $\begin{array}{c}\text { Pemasangan } \\
\text { ('000) }\end{array}$ & $\begin{array}{c}\text { Keuntungan } \\
\text { ('000) }\end{array}$ \\
\hline $\begin{array}{c}\text { Speed } \\
\begin{array}{c}\text { management/traffic } \\
\text { calming }\end{array}\end{array}$ & Present & 2,127734 & 946,2079 & Rp. 17.094,794 & Rp. 1.617.522,706 \\
\cline { 1 - 5 } $\begin{array}{c}\text { Facilities for } \\
\text { Bicycles }\end{array}$ & $\begin{array}{c}\text { Signed shared } \\
\text { roadway }\end{array}$ & & 236,552 & Rp. 17.094,794 & Rp. 4.043.807,426 \\
\hline
\end{tabular}

Tabel 15. BCR pedestrian dengan tipe kecelakaan along driver side

\begin{tabular}{cccccc}
\hline \multicolumn{5}{c}{ Pedestrian (Along Driver Side) } \\
\hline Attribute & Category & $\begin{array}{c}\text { Total } \\
\text { Reduction }\end{array}$ & BCR & $\begin{array}{c}\text { Biaya } \\
\text { Pemasangan } \\
\text { ('000) }\end{array}$ & $\begin{array}{c}\text { Keuntungan } \\
\text { ('000) }\end{array}$ \\
\hline $\begin{array}{c}\text { Speed } \\
\begin{array}{c}\text { management/traffic } \\
\text { calming }\end{array}\end{array}$ & Present & 0,044328 & 34,87606 & Rp. 17.094,794 & $\begin{array}{c}\text { Rp. } \\
404.380,742\end{array}$ \\
\hline
\end{tabular}

Tabel 16. BCR pedestrian dengan tipe kecelakaan along passanger side

\begin{tabular}{cccccc}
\hline \multicolumn{5}{c}{ Pedestrian (Along Passanger Side) } \\
\hline Attribute & Category & $\begin{array}{c}\text { Total } \\
\text { Reduction }\end{array}$ & BCR & $\begin{array}{c}\text { Biaya } \\
\text { Pemasangan } \\
\text { ('000) }\end{array}$ & $\begin{array}{c}\text { Keuntungan } \\
\text { ('000) }\end{array}$ \\
\hline $\begin{array}{c}\text { Speed } \\
\begin{array}{c}\text { management/traffic } \\
\text { calming }\end{array}\end{array}$ & Present & 0,044328 & 34,87606 & Rp. 17.094,794 & Rp. 404.380,742 \\
\hline
\end{tabular}

Tabel 17. BCR pedestrian dengan tipe kecelakaan crossing

\begin{tabular}{|c|c|c|c|c|c|}
\hline \multicolumn{6}{|c|}{ Pedestrian(Crossing) } \\
\hline Attributes & Category & $\begin{array}{c}\text { Total } \\
\text { Reduction }\end{array}$ & BCR & $\begin{array}{c}\text { Biaya } \\
\text { Pemasangan } \\
(' 000)\end{array}$ & Keuntungan ('000) \\
\hline $\begin{array}{l}\text { Number of } \\
\text { Lanes }\end{array}$ & Three & \multirow{2}{*}{8,865558} & \multirow{2}{*}{3,903108} & \multirow{2}{*}{ Rp. $518.024,088$} & \multirow{2}{*}{ Rp. $2.021 .903,713$} \\
\hline $\begin{array}{l}\text { Pedestrian } \\
\text { Fencing }\end{array}$ & Full length & & & & \\
\hline
\end{tabular}

\section{Pembahasan}

Dari hasil survei ruas jalan M.H. Thamrin menggunakan bantuan Google Street View sebagai data primer dan lalulintas harian rata-rata sebagai data sekunder yang didapat dari Instansi terkait. Maka, melalui proses coding yang dilakukan tiap segmen, dimana 1 segmen adalah setiap 100m. didapat kondisi eksisting jalan yang terbagi menjadi 10 segmen. Ruas jalan M.H. Thamrin cenderung typical atau banyak kesamaan dari segi elemen jalannya, sehingga data hasil coding segmen 1 sampai segmen 10 mempunyai banyak kesamaan.

Berdasarkan dari proses coding yang telah dilakukan, didapat hasil star rating awal kondisi eksisting ruas jalan. Hasil star rating dikategorikan untuk setiap pengguna jalan, yaitu kendaraan berpenumpang, sepeda motor, pesepeda, dan pejalan kaki. Secara keseluruhan, berdasarkan hasil star rating awal, dapat dikatakan ruas jalan sudah laik fungsi karena sebagian besar sudah mencapai star rating bintang 3. kelaikan fungsi jalan adalah untuk memastikan bahwa jalan tersebut sesuai dengan standar kelaikan sehingga berkeselamatan bagi semua pengguna jalan yang melewatinya.

Berdasarkan hasil star rating awal yang di dapat tiap segmennya, dilakukan countermeasure atau treatment pada elemen ruas jalan eksisting M.H. Thamrin untuk mancapai star rating yang diinginkan yaitu menjadi bintang 4 , selain itu countermeasure dilakukan dengan tujuan untuk untuk mengurangi korban kecelakaan, dengan berbagai 
opsi penanganan yang memiliki pertimbangan. Pada countermeasure yang dilakukan, tiap segmen nya berfokus pada fasilitas untuk pengguna sepeda motor dan pejalan kaki. Karena pada kondisi eksisting ruas jalan M.H. Thamrin dinilai masih minim fasilitas untuk pengguna sepeda motor dan pejalan kaki, sehingga menyebabkan hasil star rating awal untuk kedua pengguna jalan tersebut tergolong rendah terutama pejalan kaki yang hanya mencapai bintang 2 .

Penanganan yang dilakukan adalah dengan pemasangan pedestrian fencing, pemisahan jalur motor, pemasangan marka bagi pengguna sepeda, dan pemasangan marka batas kecepatan pemilihan ini dilakukan setelah proses trial and error dengan berbagai opsi penanganan yang ada. Dengan pemasangan treatment yang telah dipilih, maka dilakukan perhitungan Benefit Cost Rasio (BCR).

Perhitungan BCR dihitung pada tiap penanganan yang dilakukan. Pada hasil perhitungan BCR yang dilakukan pada tiap treatment, didapat hasil lebih dari 1. Artinya biaya yang dikeluarkan untuk pemasangan pedestrian fencing dan pembuatan jalur motor terpisah sebanding dengan estimasi korban kecelakaan yang dapat dicegah.

\section{KESIMPULAN DAN SARAN}

\section{Kesimpulan}

Berdasarkan hasil survey melalui bantuan Google Street View dan evaluasi menggunakan metode Internasional Road Assassment Programme (IRAP), maka didapat kesimpulan :

1. Ruas jalan M.H. Thamrin cenderung tidak terlalu banyak perbedaan dari segi elemen jalannya pada segmen 1-10. Sehingga pada proses coding jalan yang dilakukan setiap $100 \mathrm{~m}$ segmen jalan tidak terlalu banyak perbedaan pada saat input data.

2. Pemanfaatan fasilitas pejalan kaki yaitu trotoar sudah sangat baik karena bebas dari Pedagang Kaki Lima (PKL) dan parkir liar, sesuai dengan Peraturan Menteri (Permen) Pekerjaan Umum dan Perumahan Rakyat (PUPR) Nomor 03/PRT/M/2014 tentang Pedoman Perencanaan, Penyediaan, dan Pemanfaatan Prasarana dan Sarana Jaringan Pejalan Kaki di Kawasan Perkotaan.

3. Penilaian elemen jalan yang ditinjau berdasarkan empat pengguna jalan yaitu kendaraan berpenumpang, sepeda motor, sepeda, dan pejalan kaki. kondisi eksisting ruas jalan M.H. Thamrin bagi pengguna jalan dengan kategori kendaraan berpenumpang mencapai star bintang 5 pada semua segmen, artinya dari segi elemen jalan yang ada sudah terpenuhi atau berfungsi dengan baik sehingga kemungkinan terjadinya kecelakaan yang menyebabkan korban jiwa atau luka serius cenderung sedikit.

4. Penyediaan fasilitass untuk kategori pengguna jalan yaitu pejalan kaki pada ruas jalan M.H. Thamrin belum terlalu efektif untuk mengurangi tingkat fatalitas kecelakaan, terbukti dari star rating awal yang didapat yaitu bintang 2 pada sebagian besar segmen. Saat dilakukan countermeasure, upaya penananganan bagi pejalan kaki perlu di utamakan untuk meningkatkan star rating menjadi bintang 4 sehingga dapat lebih meningkatkan keselamatan bagi pejalan kaki di ruas jalan M.H. Thamrin, mengingat ruas jalan M.H. Thamrin merupakan termasuk dengan salah satu jalan utama di Jakarta dan merupakan pusat bisnis, sehingga ruas jalan M.H. Thamrin sering dilalui dan dipadati pejalan kaki.

5. Dalam upaya peningkatan star rating untuk mencapai bintang 4, terutama untuk kategori pengguna sepeda motor dan pejalan kaki. dilakukan countermeasure dengan opsi penanganan pemasangan pedestrian fencing, pemisahan jalur sepeda motor, pemasangan rambu sepeda, dan pemasangan rambu batas kecepatan. Pemilihan opsi penanganan logis untuk di realisasikan dengan mempertimbangkan biaya pemasangan dan total reduction yang dihasilkan.

6. Berdasarkan hasil perhitungan Benefit Cost Ratio, hasil yang didapat dari pemasangan treatment mendapat hasil lebih dari satu. Artinya apabila opsi penanganan direalisasikan, biaya yang dikeluarkan untuk pemasangan dan perawatan dari treatment yang dipilih selama 20 tahun akan sebanding dengan nyawa yang akan terselamatkan yaitu 19 nyawa. Hal ini merupakan keunggulan dari metode IRAP karena hasil penanganan yang dilakukan dapat langsung di evaluasi untuk biaya yang dikeluarkan, serta estimasi korban kecelakaan yang dapat dicegah, berikut dengan keuntungan dari pemasangan treatment.

\section{Saran}

Berikut merupakan saran yang dapat diberikan untuk upaya pengembangan penelitian ini lebih lanjut antara lain :

1. Survey jalan eksisting sebaiknya dilakukan secara langsung, hal ini perlu dilakukan untuk mencegah terjadinya kesalahan interpretasi elemen jalan yang tidak sesuai dengan kondisi aslinya.

2. Proses input data saat coding dan perhitungan star rating score sebaiknya dilakukan secara teliti agar terhindar dari hasil akumulasi star rating score yang salah. 


\section{DAFTAR PUSTAKA}

Mayastinasari, Vita. "PENDEKATAN SISTEM DALAM PENANGANAN KESELAMATAN JALAN." Journal of Indonesia Road Safety (2018): 39-45.

Mulyono, Agus Taufik, Berlian Kushari dan Hendra Edi Gunawan. "Audit Keselamatan Infrastruktur Jalan (Studi Kasus Jalan Nasional KM 78-KM 79 Jalur Pantura Jawa, Kabupaten Batang)." Jurnal Teoretis dan Terapan Bidang Rekayasa Sipil (2015): 163-174.

Pandey, Sisca V. "MEWUJUDKAN JALAN YANG BERKESELAMATAN." TEKNO SIPIL (2015): 30-41.

Programme,Internasional Road Assessment. "https://resources.irap.org." $14 \quad$ July 2015. https://resources.irap.org/Methodology/iRAP\%20model\%20factsheet\%2011\%20-\%20Countermeasures.pdf. 4 Oktober 2020.

—."https://resources.irap.org."13April2015. https://resources.irap.org/Methodology/iRAP\%20model\%20factsheet\%2013\%20$\%$ 20Economic\%20analysis.pdf. 10 Oktober 2020.

Rustijan and Rizky Adelwin J. MANAJEMEN KESELAMATAN JARINGAN JALAN (NETWORK SAFETY MANAGEMENT). Bandung: Kementerian Pekerjaan Umum, 2015.

Ruktiningsih, Rudatin. "Analisis Tingkat Keselamatan Lalu Lintas Kota Semarang." G-Smart (2017): 1.

Setyarini, Ni Luh Shinta Putu Eka dan Bryan Ivan Lukito. "AUDIT KESELAMATAN JALAN TOL JAGORAWI." Jurnal Muara Sains, Teknologi, Kedokteran, dan Ilmu Kesehatan (2020): 403-412.

Setyarini, Ni Luh Putu Shinta Eka dan Leksmono Suryo Putranto. "Key Factors to Become Successful Road Safety Auditor." AIP Conference Proceedings 2227 (2020).

Shinta, Ni Luh Putu, et al. "PERSEPSI PENGEMUDI TERHADAP BANGUNAN PELENGKAP JALAN DI TOL CIPULARANG." Jurnal Bakti Masyarakat Indonesia (2019): 64-73.

Sianturi, Liana Fentani Natalia dan Ni Luh Shinta Putu Eka Setyarini. "AUDIT KESELAMATAN JALAN TOL KUNCIRAN-SERPONG." Jurnal Mitra Teknik Sipil (2020): 639-650.

Sugiharto, et al. "DESAIN PENANGANAN JALAN YANG BERKESELAMATAN DI RUAS JALAN HANOMAN KOTA TEGAL." The 18th FSTPT International Symposium (2015).

Supiyono. Keselamatan Lalu Lintas Jalan Raya. Malang: POLINEMA PRESS, 2018. 